\title{
PEMBERIAN TERAPI JUS WORTEL PADA PENDERITA HIPERTENSIDI DESA BAUH GUNUNG SARI LAMPUNG TIMUR
}

DOI: https://doi.org/10.33024/jkpm.v4i5.2832

\author{
Suwarto ${ }^{1}$, Prima Dian Furqoni ${ }^{2 *}$ \\ ${ }^{1}$ Mahasiswa Profesi Ners Universitas Malahayati \\ ${ }^{2}$ Dosen Program Studi Ilmu Keperawatan Universitas Malahayati \\ Disubmit: 10 Juni 2020 Diterima: 03 Mei 2021 Diterbitkan: 03 Oktober 2021 \\ Email Korespondensi: primadianfurqoni2728@gmail.com
}

\begin{abstract}
ABSTRAK
Hipertensi merupakan masalah kesehatan dengan prevalensi yang tinggi, yaitu sebesar 25,8\%, pengobatan farmakologi, penurunan Hipertensi Pada pasien hipertensi dpat dilakukan dengan pengobatan non farmakologi. Salah satu alternatif pengobatan non farmakologi pada pasien hipertensi adalah pemberian pola makan DASH yang kaya akan kalium dan kalsium; diet rendah natrium. JNC VII menyarankan pola makan DASH yaitu diet yang kaya dengan buah, sayur, dan produk susu redah lemak dengan kadartotal lemak dan lemak jenuh .Natrium yang direkomendasikan $<2.4 \mathrm{~g}(100 \mathrm{mEq}) /$ hari. Tujuan Asuhan Keperawatan Komprehensif Pada klien Hipertensi Dengan Terapi Komplementer Jus Wortel di Desa Bauh Gunung Sari Lampung Timur Tahun 2020. Metode terapi dengan Wortel diblender 150 gram ditambah \pm 100 cc air mineral +1 sendok makan madu (sebagai pemanis ) diberikan kepada responden sebanyak \pm 200 gram /hari selama 5 hari berturut-turut pada pukul 13.00-15.00wib. masalah hipertensi teratasi dengan terapi jus wortel dengan hasil efektif pada kedua pasien hanya saja kadar penurunan tekanan darah dan waktu penurunan berbeda diantara kedua pasien dikarenakan intensitas nyeri antara kedua pasien, dan kadar tekanan darah kedua pasien yang berbeda.
\end{abstract}

Kata Kunci : Hipertensi, Komplikasi, Terapi Jus Wortel

\begin{abstract}
Hypertension is a health problem with a high prevalence, which is $25.8 \%$, pharmacological treatment, hypertension reduction in hypertensive patients can be done with non-pharmacological treatment. One alternative nonpharmacological treatment in hypertensive patients is the administration of a DASH diet that is rich in potassium and calcium; low sodium diet. JNC VII recommends the DASH diet, which is a diet rich in fruits, vegetables, and low-fat dairy products with total fat and saturated fat content. The recommended sodium is <2.4 g (100 mEq) / day. Purposeof Comprehensive Nursing Care for Hypertension clients with Complementary Carrot Juice Therapy in Bauh Gunung Sari Village, East
\end{abstract}


Lampung in 2020. Therapeutic method with Blender Carrot 150 grams plus $\pm 100 \mathrm{cc}$ mineral water +1 tablespoon of honey (as a sweetener) is given to respondents as much as $\pm 200 \mathrm{gram} /$ days for 5 consecutive days from 1:00 to 15:00 a.m. the problem of hypertension is resolved with carrot juice therapy with effective results in both patients except that the level of blood pressure drops and the time of decrease is different between the twopatients due to the intensity of pain between the two patients, and the blood pressure levels of the two patients are different.

Keywords: Hypertension, Complications, Carrot Juice Therapy

\section{PENDAHULUAN}

Hipertensi merupakan masalah kesehatan dengan prevalensi yang tinggi, yaitu sebesar 25,8\%, sesuai dengan data Riskesdas 2013. Hipertensi atau tekanan darah tinggi adalah peningkatan tekanan darah sistolik lebih dari $140 \mathrm{mmHg}$ dan tekanan darah diastolik lebih dari $90 \mathrm{mmHg}$ pada dua kali pengukuran dengan selang waktu lima menit dalam keadaan cukup istirahat/tenang. (Kemenkes RI, 2015).

Komplikasi yang terjadi pada penderita hipertensi selain mengakibatkan gagal jantung, hipertensi dapat berakibat terjadinya gagal ginjal maupun penyakit serebrovaskular. Hipertensi juga menimbulkan angka morbiditas (kesakitan) dan mortalitas (kematian) yang tinggi hingga dijuluki sebagai The Silent Killer (Nuraini, 2015). Tekanan darah tinggi sebagai penyebab utama atau berkontribusi. hampir 1.000 kematian setiap hari di Amerika, tekanan darah tinggi meningkatkan risiko kesehatan yang berbahaya sepertisekitar 7 dari setiap 10 orang mengalami serangan jantung, sekitar 8 dari setiap 10 orang mengalami stroke pertama mereka memiliki tekanan darah tinggi, sekitar 7 dari setiap 10 orang dengan gagal jantung kronis dan penyakit ginjal juga merupakan faktor risiko utama untuk tekanan darah tinggi (CDC, 2016).

Di seluruh dunia, Peningkatan tekanan darah diperkirakan menyebabkan 7,5 juta kematian, 12,8\% dari 69 juta total semua kematian. Ini menyumbang57 juta disability adjusted life years (DALYS) atau 3,7\% dari total DALYS (WHO, 2017). Sekitar 972 juta orang atau $26,4 \%$ orang di seluruh dunia mengidap hipertensi, angka ini kemungkinan akan meningkat menjadi 29,2\% di tahun 2025, dari 972 juta pengidap hipertensi, 333 juta berada di Negaramaju dan 639 sisanya berada di negara berkembang, termasuk Indonesia (Yonata, 2016).

Prevalensi hipertensi di Indonesia berdasarkan hasil pengukuran pada umur $\geq 18$ tahun sebesar 25,8\%. Provinsi Aceh (30,9\%), Provinsi Riau (30,8\%), JawaBarat $(29,4 \%)$ dan Provinsi Sumatra Utara $(29,0 \%)$ menduduki urutan 5teratas prevalensi hipertensi. Pada tahun 2018 diketahui bahwa penderita hipertensi usia 18-44 tahun sebesar 64.9\% (Riskesdas, 2018).

Berdasarkan Profil Kesehatan Provinsi Lampung, 2017 hipertensi merupakan penyakit ke 3 dari 10 besar penyakit di Provinsi Lampung, dengan jumlah 230.672. Jumlah hipertensi terbanyak pada tahun 2016 pada Kabupaten Lampung Tengah 20.718, di susul dengan kabupaten Lampung Selatan 17.804, Lampung Timur 14.522, dan Kota Bandar Lampung 5.906. Pada Tahun 2017 Bandar Lampung menduduki jumlah Hipertensi Tertinggi denganjunlah 25.011, dan Kabupaten Pesawaran 12.610 penderita.

Faktor-faktor yang mempengaruhi terjadinya hipertensi dibagi dalam dua 
kelompok besar yaitu faktor yang tidak dapat dikendalikan seperti jenis kelamin, umur, genetik, ras dan faktor yang dapat dikendalikan seperti polamakan, kebiasaan olah raga, konsumsi garam, kopi, alkohol dan stres.Untuk terjadinya hipertensi perlu peran faktor risiko tersebut secara bersama-sama (common underlying risk factor), dengan kata lain satu faktor risiko saja belum cukup menyebabkan timbulnya hipertensi (Asdie, 2012).

Wortel merupakan bahan pangan (sayuran) yang digemari dan dapat dijangkau oleh seluruh lapisan masyarakat. Bahkan mengkonsumsi wortel sangat dianjurkan, terutama untuk menghadapi masalah kekurangan vitamin A. Vitamin A dan beta-karoten merupakan komposisi wortel yang paling dominan. Menurut Bayu (2013) wortel sebagai bahan makanan yang penuh gizi. Umbi wortel banyak mengandung vitamin $\mathrm{A}, \mathrm{B}, \mathrm{C}, \mathrm{D}, \mathrm{E}$, dan $\mathrm{K}$.

Selain itu, juga mengandung mineral - mineral penting bagi tubuh seperti kalsium, zat besi, fosfor, klorin, sulfur, silikon, megnesium, dan niacin.selain kaya akan kalium, wortel juga mempakan sumber beta karoten yang tinggi. Oleh karena itu, worter sangat ampuh untuk mengontrol hipertensi dan baik untuk dikonsumsi penderita hipertensi Lubna, (2016).

\section{MASALAH}

Alasan saya memilih tempat penyuluhan kesehatan tentang terapi jus wortel dalam menurunkan hipertensi di Desa Bauh Gunung Sari Lampung Timur. saya memilih penelitian tentang efektifitas terapi jus wortel ini dikarenakan banyaknya masalah dalam kesehatan keluarga dengan hipertensi, dan cara untuk tetap mengontrol tekanan darah tanpa menggunakan farmakologi dalam waktu jangka panjang. Dimana tujuanumum dalam penelitian mampu melaksanakan asuhan keperawatan komprehensif terhadap penderita hipertensi dengan menggunakan terapi jus wortel, Dan tujuan khusus dalam kegiatan yaitu klien mengerti dan memahami pengertian hipertensi, mengerti dan memahami cara penanganannya, mengerti dan memahami pencegahan, dan mengetahuipengobatan hipertensi.

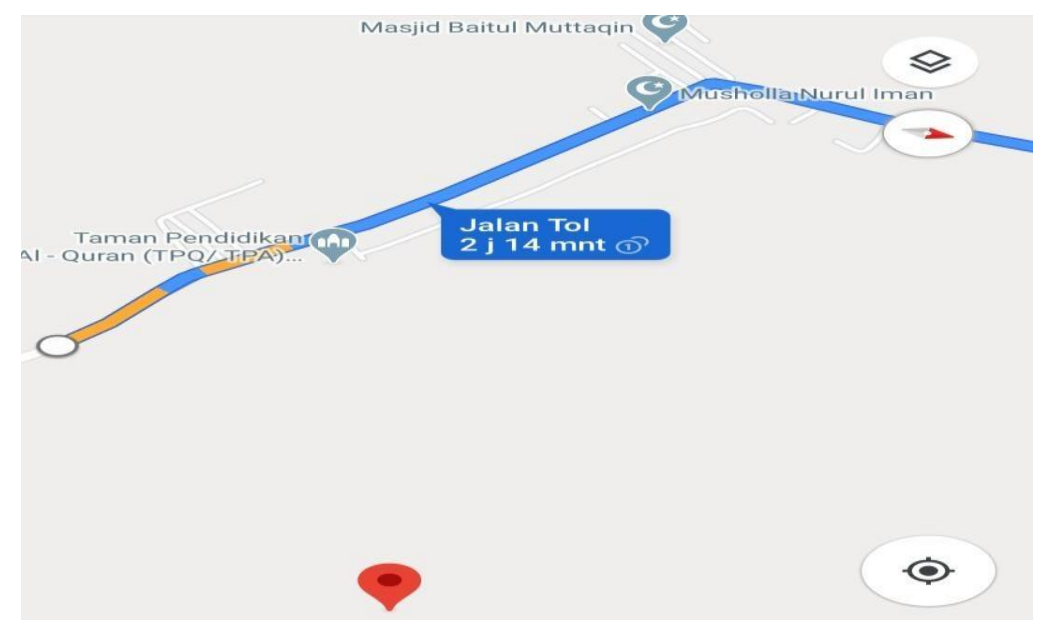

Gambar 2.1 Lokasi Penyuluhan Kesehatan Desa Bauh Gunung Sari LampungTimur 


\section{METODE}

1. Tujuan Persiapan

Tahap persiapan dari kegiatan adalah pembuatan pre planing, persiapanpenyajian, tempat dan alat - alat lainnya saya siapkan sendiri. Alat : Blender, sendok makan, Bahan : Wortel 150 gram, $\pm 100 \mathrm{cc}$ air mineral, madu (sebagai pemanis ). dimulai pada hari selasa tanggal 24 April 2020, pada tanggal 24 April 2020 dilakukan pengecekan untuk persiapan penyuluhan kesehatan hipertensi dan Pendemonstrasian tentang pengobatan nonfarmakologi terapi jus wortel.

\section{Tahap Pelaksanaan}

Acara ini dengan pemberitahuan kepada keluarga Ny. M, dan Ny. K di laksanakan kegiatan pada tanggal 25 April 2020. Dan dilanjutkan Pendemonstrasian tentang pengobatan nonfarmakologi terapi juswortel.

3. Evaluasi

a. Struktur

Peserta hadir sebanyak 2 orang yng terdiri dari Ny. M dan Ny. K. Setting tempat sudah sesuai dengan rencana yang dibuat dan perlengkapan yang dilakukan untuk penyuluhan sudah tersedia dan sudah digunakan sebagaiman mestinya.

b. Proses

Pelaksanaan kegiatan pukul 14.30 s/d 15.30 wib. Sesuai dengan jadwal yang telah direncanakn.

c. Hasil

1. Peserta dapat memahami dan mengerti tentang pengertian Hipertensi dan pemberian terapi jus wortel.

2. Peserta dapat memahami tujuan pemberian terapi juswortel.

3. Peserta dapat memahami dan mengerti manfaat dantehnik pembuatan jus wortel.

4. Peserta dapat memahami dan mengerti tentang langkah -langkah pembuatan jus wortel.

\section{HASIL PENELITIAN}

Metode pelaksanaan dalam kegiatan penyuluhan ini dilaksanakan pada tanggal 25 April 2020 di desa Bauh Gunung Sari Lampung Timur. Pelaksanaan penyuluhan ditujukan pada keluarga Ny. M dan Ny. K. alat dan bahan yang disediakan berupa Alat : Blender, sendok makan, Bahan :Wortel 150 gram, $\pm 100 \mathrm{cc}$ air mineral, madu (sebagai pemanis ) Wortel 150 gram diblender ditambah $\pm 100 \mathrm{cc}$ air mineral + 1 sendok makan madu (sebagai pemanis ) diberikan kepada responden sebanyak \pm 200 gram / hari selama 5 hari berturut-turut pada pukul 13.00-15.00wib. Dan metode yang digunakan adalah ceramah dan tanya jawab atau evaluasi mengenai kesehatan. Data yang di dapat saat sebelum minum jus wortel pada klien 1 TD : 160/100 mmHg, pada klien 2 TD : 150/90 mmHg. Dan setelah minum jus wortel sebanyak $\pm 200 \mathrm{ml} /$ hari selama 5 hari berturut-turut pada pukul 13.00 15.00wib di dapat hasil pada klien $1 \mathrm{TD}: 140 / 90 \mathrm{mmHg}$ yang penuruan membutuhkan 
waktu sedikit lebih lama, dan pada klien ke 2 di dapat TD : 120/80mmHg, klien ke 2 mengalami penurunan. Hasil evaluasi pada pasien ke-1 terapi Jus wortel kurang efektif dan penurunan darah tidak signifikan, penurunan tekanan darah dapat menurun hanya saja memerlukan waktu lebih lama dari pasien yang pertama, dan Peningkatan tekanan darah masih dalam katagori hipertensi yang memerlukan pengobatan lain,seperti obat penurun hipertensi. Berikutgambar pelaksanaan penyuluhan:
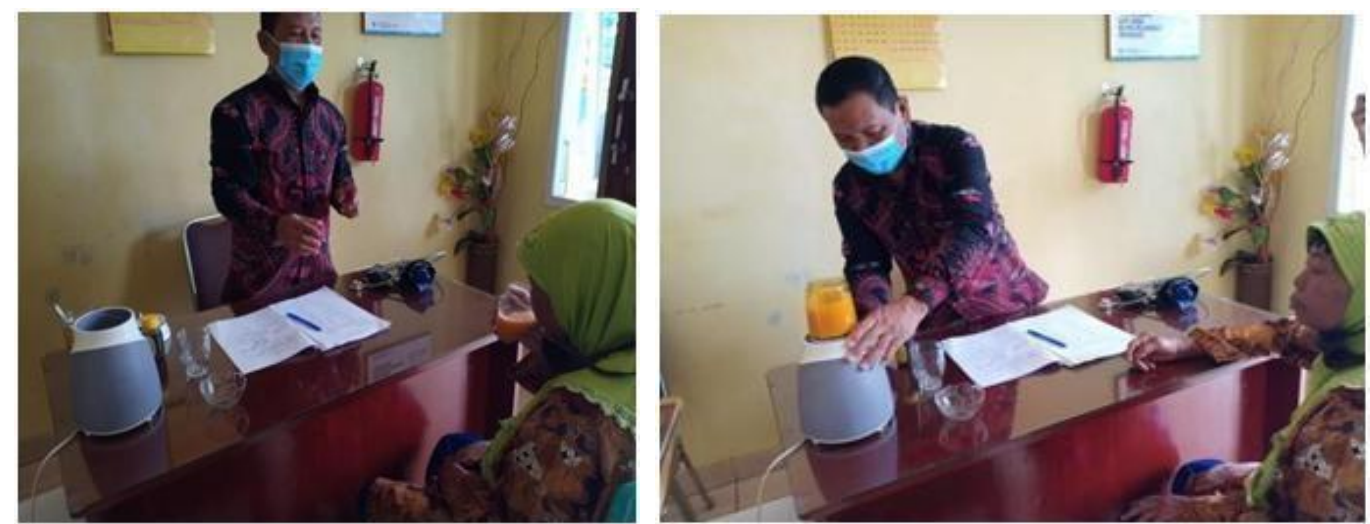

Gambar 4.1. Pelaksanaan Penyuluhan dan pendemonstrasian

\section{KESIMPULAN DAN SARAN}

Terapi non farmakologi pemberian jus wortel terbukti dapat menurunkanhipertensi. Hal ini membuktikan beberapa hasil penelitian yang pernah dilakukan kepada klien hipertensi, bahwa pemberian jus wortel dapat dijadikan alternatif perawatan hipertensi yang murah, mudah, dan aman.

\section{DAFTAR PUSTAKA}

Apriliyasari, R. W., \& Prasetyo, A. S. (2013). Pengaruh Pemberian Terapi Klenengan Gending Jawa Terhadap Memori Jangka Pendek pada Pasien dengan Stroke Iskemik di RSUD Kudus Tahun 2013. Jurnal Keperawatan dan Kesehatan Masyarakat Cendekia Utama, 2(2).

American Heart Association. (2013). Heart Disease \& Stroke Statistics-2013 Update, American Heart Association. Texas Diakses pada https: //www.ncbi.nlm.nih. gov/pubmed/ tanggal 4 Jjuni 2018

Arum.(2015). STROKE, Kenali, Cegah dan Obati. Yogyakarta : Notebook

Asdie Ahmad Horrison (ed) edisi Indonesia. K. J. Isselbacher, E. Braunwald, J.D. Wilson, J.B. Martin, A.S. Fauci, D.L. (2012). Prinsip-prinsip Ilmu Penyakit Dalam Volume 3 Edisi 13. Jakarta : EGC.

Depkes RI. 2018. Hasil Riskesdas 2018- Departeman Kesehatan Republik Indonesia. Diakses dari: http: //www.depkes.go.id/.pdf.

Hawari, D. (2013). Pendekatan Holistik pada Gangguan Jiwa Skizofrenia. Jakarta: Balai Penerbit FKUI

Junaidi I. (2004). Stroke A-Z. Jakarta: Gramedia

Murtisari, Y. (2014). Pengaruh Pemberian Terapi Klenengan Gending Jawa Terhadap Penurunan Tingkat Depresi Pada Pasien Stroke Non Hemoragik Di Rsud Salatiga. Karya Ilmiah. 
Nursalam. (2016). Manajemen Keperawatan.edisi 3. Jakarta : Salemba Medika.

Price Sylvia A, Wilson Lorraine M. Patofisiologi: Konsep Klinis. Proses-Proses Penyakit. Jakarta: EGC; 2012

Rukmana, A., \& Udani, G. (2017). Tekanan Darah Pada Penderita StrokeNon Hemoragi Dengan Terapi Musik. Jurnal Ilmiah Keperawatan Sai Betik, 9(2), 109-114.

Solehati, Tetti \& Eli Kokasih, Cecep. 2015. Konsep dan Aplikasi Relaksasi Dalam Keperawatan. Maternitas. Bandung: PT Refika Aditama

Smeltzer, Suzanne C. dan Bare, Brenda G, 2002, Buku Ajar Keperawatan Medikal. Bedah Brunner dan Suddarth (Ed.8, Vol. 1,2)

Sari, Yanita Nur Indah. (2017). Beramai Denganstroke Jakarta: Bumi Medika.

Susilo, Yekti dr., Ari Wulandari. (2011). Cara jitu mengatasistroke Andi: Yogyakarta

Setyoadi., Kushariyadi. (2011). Terapi Modalitas Psikogeriatrik. Jakarta: Salemba Medika

Kementerian kesehatan RI. (2014). INFODATIN Pusat Data dan Informasi Kemeterian. Kesehata 1 'n RI Situasi Kesehatan Jantung.

Stuart, G. W., Sundeen, JS. (2009). Keperawatan jiwa (Terjemahan), alih bahasa: Achir Yani edisi III. Jakarta : EGC

Widyo, Kriswanto. (2014). Klasifikasi Stroke. Available from http://www.neurobethesda.com/klasifikasi-stroke/. Diakses pada tanggal 26 Mei 2018.

Wijanarko, M. O. A., Setyawan, D., \& Kusuma, M. A. B. (2017). Pengaruh Terapi Klenengan Gending Jawa Terhadap Pasien Stroke Yang Menjalani Latihan Range of Motion (ROM) Pasif. Karya Ilmiah.

Zakiah. (2015). Konsep Dasar Nyeri. Jakarta : Salemba Medika 